\title{
Kein vorschneller Griff zum Antibiotikum
}

\author{
Das Thema Antibiotika-Resistenzen gewinnt an politischer Aufmerksamkeit - doch hat das Aus- \\ wirkungen auf den Praxisalltag? Springer Medizin hat vier Ärzte aus verschiedenen Fachgruppen \\ gefragt. Für die Hausärzte gab Dr. Margit Hollenz ihre Einschätzung ab.
}

\section{MMW: Ein Zehn-Punkte-Plan von Minister Gröhe, die Deutsche Antibio- tika-Resistenzstrategie 2020, ein Bekenntnis beim G7-Gipfel - die große Politik hat sich in den vergangenen Monaten intensiv mit dem Thema Antibiotika-Resistenz befasst. Was ist davon in Ihrer Praxis angekommen?}

Hollenz: Von der großen Politik relativ wenig. Ich glaube auch, dass meine Kollegen sich wenig mit der politischen Seite der Antibiotika-Resistenz beschäftigen. Wir sehen den Patienten, und für uns zählt das Individuum und nicht die globale Resistenzlage. Die müssen die Politiker lösen. Aber wir wissen alle, dass es für den Patienten immens wichtig ist, dass wir sehr sorgfältig mit der Antibiotika-Verordnung umgehen.

MMW: Die Politik redet, Ärzte müssen handeln - wie gehen Sie bei der Therapie von Atemwegsinfekten vor, um der Entstehung von Antibiotika-Resistenzen entgegenzuwirken?

Hollenz: Das Primäre ist, dass der $\mathrm{Pa}$ tient von Individuum zu Individuum und von Krankheitsfall zu Krankheitsfall unterschiedlich ist. Als erstes schaue ich, wo die Hauptsymptomatik ist, ob etwa bei einem Infekt der oberen Luft- wege die Symptome mehr im Bereich von Nase und Rachen liegen oder mehr die bronchiale Situation im Vordergrund steht. Dann frage ich nach anamnestisch wichtigen Dingen. Ich muss natürlich bei chronischen Grunderkrankungen anders vorgehen als bei Patienten, die keinerlei Belastungen haben.

\section{MMW: Welchen Stellenwert haben Phytopharmaka in Ihrer Praxis bei der Behandlung von Atemwegsinfekten?}

Hollenz: Bei einer Diagnose unkomplizierter Infekte der oberen Luftwege steht für mich die Phytotherapie an erster Stelle - schon seit 35 Jahren, und nicht erst seit ich von der Resistenzentwicklung gehört habe. Bei solchen unkomplizierten Infekten wähle ich je nachdem, wo die Symptomatik am stärksten ausgeprägt ist, das passende Phytopharmakon. Ganz wichtig ist meiner Meinung nach auch, dem Patienten die Wirkweise $\mathrm{zu}$ verdeutlichen. Man muss genau erklären, was das Mittel macht, damit der Patient auch am Ball bleibt. Und ich spare damit mit Sicherheit im Interesse des Patienten Antibiotika ein.

MMW: Wo stehen nach Ihrer Einschätzung die Allgemeinmediziner, wenn es

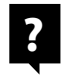

Dr. Margit Hollenz Fachärztin für Allgemeinmedizin, Rödental

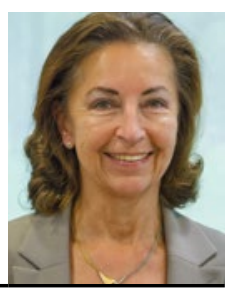

um den rationalen Einsatz von Antibiotika geht? Sind sie Vorreiter oder Schlusslicht?

Hollenz: Ich denke leider: Schlusslicht. Seit ich mich mit der Thematik intensiv beschäftigte, habe ich einmal kritisch das Verhalten meiner Kollegen beäugt. Ich habe leider schon den Eindruck, dass viel zu schnell zum Antibiotikum gegriffen wird, wo ich an der Stelle immer erst das Phytotherapeutikum eingesetzt hätte. Deswegen denke ich, dass hier noch viel Informationsarbeit zu leisten ist. Wenn ein Patient mir sagt, dass er aber nächste Woche zum Radfahren gehen will und deshalb schnell gesund werden muss, dann ist ihm ja nicht damit gedient, wenn ich mich davon beeinflussen lasse und fälschlicherweise ein Antibiotikum einsetze.

Interview: Andrea Wehrens

Das vollständige Interview mit Dr. Hollenz können Sie unter www.springermedizin.de/link/10369580 als Video ansehen. Dort finden Sie auch Interviews mit Kollegen aus Innerer Medizin, Pädiatrie und HNO-Heilkunde - zu den gleichen Fragen.
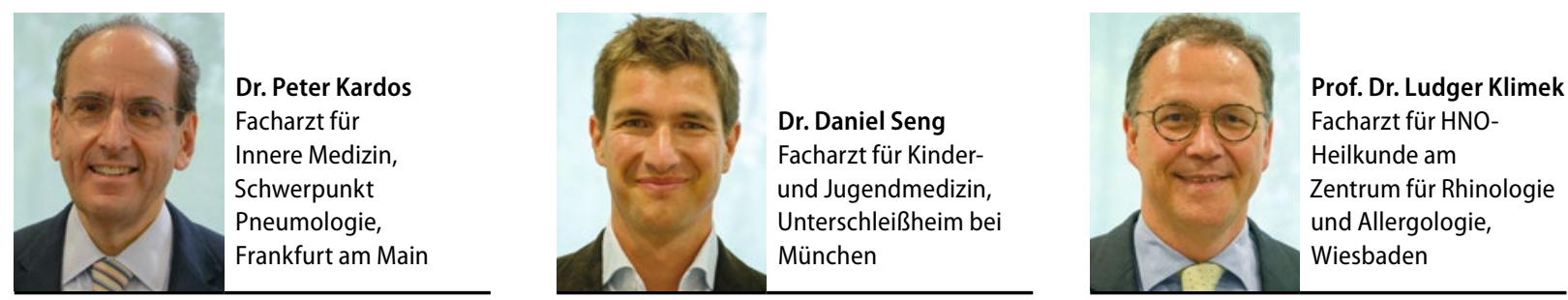